\title{
Effect of Tutorial on Students' Communication Skill in Google Classroom in University of Port Harcourt
}

\author{
Sandra Eberechukwu Augustine ${ }^{1 *}\left(\mathbb{C}\right.$, Lois Nkechi Abraham ${ }^{1}$ (i)
}

${ }^{1}$ Department of Curriculum Studies and Educational Technology, University of Port Harcourt, NIGERIA

*Corresponding Author: sandra.augustine@uniport.edu.ng

Citation: Augustine, S. E., \& Abraham, L. N. (2021). Effect of Tutorial on Students' Communication Skill in Google Classroom in University of Port Harcourt. Mediterranean Journal of Social \& Behavioral Research, 5(3), 51-57. https://doi.org/10.30935/mjosbr/11292

\begin{abstract}
This study established students' communication skills level in Google classroom in the Faculty of Education, University of Port Harcourt. The study used one group pretest-post-test pre-experimental research design and a sample size of 70 students from the Department of Educational Management, selected via purposive sampling technique. Two (2) research hypotheses guided the study. Google Classroom Communication Skills Test (GCCST), with a reliability coefficient of 0.87 , was the instrument for data collection. Sign test and Quade's Analysis of Covariance were for analyzing data. The results showed that the students' communication skill level in Google classroom increased and significantly higher due to the tutorial on Google classroom utilization. However, the students' communication skills level in Google classroom did not significantly differ based on gender. The results led to the recommendation that instructors expose students to the basic skills required to use and communicate effectively in every online learning platform before adopting such for instructional purposes.

Keywords: online learning, Learning Management System (LMS), Google classroom, communication skill, tutorial Received: 5 May 2021 Accepted: 7 Sep. 2021
\end{abstract}

\section{INTRODUCTION}

Education should be made accessible, flexible, and sociable to contemporary learners, whose frequent presence in the digital space is unquestionable, with brains wired over the social networks. Digitalization of education remains the best way of improving teaching/learning in this technological age. The era when teaching/learning is restricted purely to the physical classroom environs has long eluded owing to the proliferation of Information and Communication Technologies (ICTs) and online instructional platforms. Online teaching/learning, as one of the trending innovations in the education system, has necessitated the development of many online instructional platforms or Learning Management Systems (LMSs) in recent years to facilitate online course development, delivery, and management of courses and learners' progress. Most of these LMSs (Google classroom, as a sample) are free and available for teachers to adapt for online instructional purposes.

Google Classroom is a classroom that was created and hosted by Google for online teaching and learning. Google Classroom is a tool in the Google Apps for Education (GAFE) that works with other Google applications such as Google Mail (Gmail), Doc, Drive, Form, sheet, among others. It is accessible via a Google account. Google Classroom can be downloaded and installed as an application in android and smartphones from Google Play and Apple stores, respectively, or accessed directly through the website https://classroom.google.com/ using whichever browser in an Internet-connected computer. Teachers can use this online classroom to create a class where they can add learning materials (in textual, hyperlinks, video, audio, or image formats), discussion questions, assignments, and quizzes with due dates, post announcements, grade assignments, and provide students with timely feedback. Students can join a class through each class-generated code or by email invitation from a teacher. Google Classroom gives students easy access to course contents, allows them to share learning materials, post information or comment on other people's work, turn in assignments, and access their grades and teacher's feedback. Google classroom, therefore, promotes a paperless education system and serves as an online platform where teachers and students meet to exchange ideas and interact in real and odd times. Bell (2015) affirms that Google vendors created Google Classroom to assist educators and learners to have limitless opportunities for online collaboration, communication, management of paperless assignments, and organize their teachings. Unicheck Team (2017) noted that Google classroom helps students to utilize learning time effectively and to learn at a faster rate.

Google Classroom has many features that promote effective class communication and learning for both learners and teachers. The most visible features available to students joining the online classroom are Stream, Classwork, People, and Grade pages. Stream page contains class notifications on announcements, course works, and posts or comments starting from the most recent. Students can equally use the Stream page 
to submit assignments, share questions or information to the class through posts or comments. The Classwork page contains course works, assessments, and questions organized by units or topics. The people page has the names and pictures of all the teachers and students who are members of a class, and this page allows class members to establish private communication with one another through email. The Grade page is where students see their scores on any assignments or answer questions they have submitted to the class. The grade page is where students can see their scores on any graded questions, quizzes or assessments, and filters the status (such as grade, missing, or turned in) of their works.

Google classroom also contains symbolic features that allow students to attach and upload images, files, videos, or links, either from Google Drive or computer to their posts when clicked. From other features available in Google classroom, students can delete posts or comments they have created, reply to comments, send private comments to their teachers from the assignments in the Classwork page, mention their class members in their posts, answer questions, and also see assignments and notifications and in the class calendar. Google Classroom serves as a platform to manage assignments in paperless form. Students have great opportunities to submit their assignments to their teachers online, either with or without a file attachment. Submitting an assignment with a file attachment requires clicking the 'Turn in' feature; submitting an assignment without a file attachment requires clicking the 'Mark as done' feature. Students can also edit assignments submitted before the assignment due date by clicking the Unsubmit button, effect corrections, and resubmit the assignment.

Nevertheless, for students to understand the features and affordances of Google classroom and use it for interactions and learning effectively, it might be expedient for them to develop adequate online communication abilities. Communication is the exchange of information from one person to another through a medium like Google classroom. Therefore, students' high communication skills level in any online instructional tool may go a long way to prove their readiness to study using such a tool.

Previous researchers have conducted some studies related to students' communication skills level. Among these are those of Quail et al. (2016), who examined students' communication knowledge, skill, and assurance in online, standardized patients, and conventional training environments. Their results indicated that the students' communication knowledge, skill, and assurance were higher after they were placed across the different learning environments. Bin Mohd Jalaludin and Bin Ihkasan (2014) carried out a study in a Malaysian University to investigate undergraduates' interpersonal communication skills level and found that students' interpersonal communication skills' level is high with a significant difference de gender. Iksan et al. (2012) investigated students' communication skills level in the University of Kebangsaan Malaysia and discovered that the students' communication skill level was good. Jannatul-Ferdows and Ahmed (2015) investigated the University of Dhaka undergraduates' information skills and their findings indicated a poor level of students' information skills, which differed significantly based on age, gender, and computer literacy. Negin et al. (2016) investigated the effectiveness of person-to-person communication skills on Karaj city students' social development and established that at pre-test, there was a positive and significant effect of training on interpersonal communication skills on experimental group's social growth. Critical examination of the above studies showed that none has looked into students' communication skills level in Google classroom, which resulted in this study.

\section{Statement of the Problem}

Adopting online instructional tools is necessary for every teacher to bridge the communication, inflexibility, social interaction, and time restriction gaps inherent in the conventional classroom system. Many educators have utilized different online learning tools (especially the free ones) to blend their courses and make students have online learning experiences. Although these online learning platforms may serve their purposes, one could easily observe the difficulties learners and even teachers face in trying to understand their various features and functionalities, navigate around the environment to access learning content and interact with others, answer questions, submit assignments, and even access their grade. All these may take learners some hours (for faster learners), days to weeks (especially for slow learners) to understand where proper orientation and guidance are absent. The inability to understand online learning platform features may cause unserious students to abandon their studies and hinder effective communication and full participation in an online learning experience. Therefore, mere choosing and using any online instructional platform may not adequately facilitate students' learning, but the students' ability to communicate and use it may help to yield a better result.

This study, therefore, asked, can exposing students in the Faculty of Education at the University of Port Harcourt to a tutorial on Google classroom utilization help them acquire the adequate communication skills level they need in the learning platform?

\section{Aim and Objectives of the Study}

The general aim of this study was to ascertain the effect of a tutorial on students' communication skills level in Google classroom in the Faculty of Education, University of Port Harcourt. In specific terms, the study sought to:

1. determine the effect of a tutorial on students' pretest and posttest communication skills levels in Google classroom.

2. find out the effect of a tutorial on male and female students pretest and post-test communication skills levels in Google classroom.

\section{Hypotheses}

The null hypotheses' testing was at 0.05 alpha level.

1. The tutorial effect on students' pretest and post-test communication skill levels in Google classroom did not differ significantly.

2. The tutorial effect on male and female students' pretest and post-test communication skills levels in Google classroom did not differ significantly.

\section{METHODOLOGY}

\section{Research Design}

The design of this study was one group, pretest-post-test preexperimental research design. 
Table 1. Sign t-test of students' pretest and post-test communication skills levels

\begin{tabular}{|c|c|c|c|c|c|c|c|}
\hline & & $\mathbf{N}$ & df & $\mathbf{Z}$ & P-value & Effect Size (r) & Decision \\
\hline \multirow{4}{*}{ Posttest - Pretest } & Negative Differences $^{a}$ & 5 & & & & & \\
\hline & Positive Differences ${ }^{b}$ & 62 & 69 & 6.84 & 0.00 & 0.82 & Reject \\
\hline & Ties $^{c}$ & 3 & & & & & \\
\hline & Total & 70 & & & & & \\
\hline
\end{tabular}

a. Posttest $<$ Pretest

b. Posttest $>$ Pretest

c. Posttest $=$ Pretest

\section{Population of the Study}

The population was 140 students from the Department of Educational Management, Faculty of Education at the University of Port Harcourt in the 2019/2020 academic session.

\section{Sample and Sampling Technique}

The study used a sample size of seventy (70) students selected through a purposive sampling method because they had android phones where they downloaded and installed Google classroom application.

\section{Statistical Analysis}

Sign test and Quade's Analysis of Covariance (Non-parametric ANCOVA) were the statistical tools used to test hypotheses 1 and 2, respectively. Sign test suits hypothesis 1 because it tests the differences in the pretest and post-test median values for the one group of students on a continuous scale measurement and non-symmetrical distribution. Quade's ANCOVA suits hypothesis 2 because it tests the gender effect on students' communication skills after removing the pretest (covariate) with unsymmetrical data. Kolmogorov-Smirnov and Shapiro-Wilk normality tests with $0.00 \mathrm{p}$-value (see Appendix 3 ) and Levene's test of homogeneity of variance (for covariate) with a $0.42 \mathrm{p}$ value based on median (see Appendix 4) proved that hypothesis 2 met the assumption for Quade's ANCOVA.

\section{Research Instrument}

The researchers constructed a twenty (20) item-test instrument titled Google Classroom Communication Skills Test (GCCST) and used it for data collection. GCCST contained two sections (A and B). Section A was for students' demographic data collection, and section $B$ contained twenty objectives questions, which centered on students' ability to communicate in, navigate around and use the Google Classroom. Nineteen (19) of the objective questions have options $a, b$, $\mathrm{c}$, and d, with one correct answer and three distracters, while one objective question had True or False options. Each correct answer in section B of the GCCST carries five (5) marks, giving 100 percent for all correct answers. Therefore, a mean value of 50 and above indicates a high communication skill level, and a mean value below 50 indicates a low communication skill level. QGCCST was face and content validated by giving it to two Educational Technologists in the Department of Curriculum Studies and Educational Technology at the University of Education who provided suggestions that helped the researchers to improve the instrument. QGCCST was tested for reliability through the Kuder-Richardson 21 method to get an alpha reliability coefficient of 0.87 .

\section{Procedure}

The researchers administered GCCST to the respondents as a pretest before training them on Google classroom usage. The researchers gave the respondents training on how to communicate and use the Google classroom for one week. The researchers exposed the respondents to graphics-filled PowerPoint presentations that explain Google classroom's meaning, how to install the classroom on mobile devices, sign in to Google classroom, join a class; identify the Google classroom features, share information to the classroom with and without file attachment; submit assignments; answer questions; see grades and classwork in one place; and email teacher and classmates from the Google classroom. During the presentation, the researchers asked the respondents to create a Gmail account (for those who did not have one), download the Google classroom into their mobile devices, sign in and join a class on the Computer in Education course that the researchers already created. The researchers gave the respondents five days to navigate and get familiarized in the classroom, interact among themselves by posting information on the classroom, answer questions and perform other activities they desire in the Google classroom. After the training period, the researchers re-administered the GCCST to the respondents as post-test, collated, and subjected for analysis. The researchers received help from two research assistants during the data collection process.

\section{RESULTS}

Hypothesis 1: The tutorial effect on students' pretest and post-test communication skills levels in Google classroom did not differ significantly.

Table 1 shows that 5, 62 and 3 of the students had decreased, increased and no change, respectively, in their online communication skills levels at post-test. There is also a p-value of 0.00 , which is higher than the 0.05 alpha value at $\mathrm{df}$ of 69 with a 0.82 effect size (see Appendix 3 for effect size calculation). This $0.00 \mathrm{p}$-value led to the rejection of the hypothesis that states that the effect of a tutorial on students' pretest and post-test communication skill levels in Google classroom did not differ significantly. Thus, there is a positive and significant effect of tutorial on students' communication skill level in Google classroom with a high effect size of 0.82 .

Hypothesis 2: The tutorial effect on male and female students' pretest and post-test communication skills levels in Google classroom did not differ significantly.

Table 2 shows that the $\mathrm{p}$-value of 0.56 is higher than the 0.05 alpha value. This $0.56 \mathrm{p}$-value leads to the acceptance of the hypothesis that states that the tutorial effect on the male and female students' pretest and post-test communication skill level in Google classroom did not differ significantly. Thus, the tutorial effect on the students' communication skills level in Google classroom did not significantly differ based on gender. 
Table 2. Quade's ANCOVA on students' pretest and post-test communication skills levels based on gender

\begin{tabular}{cccccccc}
\hline & \multicolumn{4}{c}{ Dependent Variable: Unstandardized Residual } & & Partial Eta Squared & Decision \\
\hline Source & Type III Sum of Squares & df & Mean Square & F & Sig. & . \\
\hline Corrected Model & $134.549^{\mathrm{a}}$ & 1 & 134.55 & 0.34 & 0.56 & .005 & .000 \\
\hline Intercept & .439 & 1 & .44 & 0.00 & 0.97 & .005 & Accept \\
\hline Gender & 134.549 & 1 & 134.55 & 0.34 & $\mathbf{0 . 5 6}$ & \\
\hline Error & 26849.270 & 68 & 394.84 & & & &
\end{tabular}

\section{DISCUSSION}

Table 1 showed that the students' communication skill level in Google classroom increased and was significantly higher at post-test with a high effect size. This implies that the tutorial on using Google classroom gave the students more knowledge and skills on how to use and communicate adequately in the Google classroom. Thus, exposing students to some training on the use of an online learning application before utilization helps them to acquire necessary skills that promote their smooth transition to online learning experiences. These results tally with that of Quail et al. (2016), Bin Mohd Jalaludin and Bin Ihkasan (2014), and Iksan et al. (2012) that reported higher levels of students' communication knowledge, skill, and assurance after placement in the different learning environments; and that of Linjawi and Alfadda (2018) who noted that students had a high level of computer skills. The results of Bin Mohd Jalaludin and Bin Ihkasan (2014), Jannatul-Ferdows and Ahmed (2015), Linjawi and Alfadda (2018) studies, and Negin et al. (2016), who found that at post-test, there was a positive and significant effect of training on interpersonal communication skills on experimental group's social growth agreed with this study's findings. These results differed from that of Jannatul-Ferdows and Ahmed (2015), who reported that students had a poor information skills level.

Table 2 has shown that the tutorial on Google classroom utilization has an insignificant effect on the male and female students' communication skills levels in Google classroom. This result signifies that gender does not determine students' communication skills when using online learning platforms. This finding differs from that of Jannatul-Ferdows and Ahmed (2015) that students' information skills differed significantly based on gender.

\section{CONCLUSION}

This study has investigated the effect of a tutorial on students' online communication skill level in Google classroom. The findings proved that giving tutorial on Google classroom utilization was significantly effective in increasing students ability to use and communication effectively in the online learning platform. The gender does not have any significant effect on how the students learn and utilize the Google classroom. Thus, tutorial play a significant role on improving students' rate of communication, involvement, and use of online learning platforms for learning purposes irrespective of their gender.

\section{RECOMMENDATION}

The recommendations that support the findings of this study include:
1. Students should be exposed to the basic skills required to use and communicate effectively in every online instructional platform before adopting such for instructional purposes.

2. University lecturers should use online learning tools such as Google classroom in their instructional process so that all students, irrespective of their gender will be adequately acquainted with online communication skills.

3. Future researchers should investigate the effect of tutorials on other online learning platforms.

4. Future researchers should study students' perceptions for using the Google classroom for learning purposes.

\section{LIMITATION OF THE STUDY}

1. There was an insufficient sample size for the study since all the students in the Department of Educational Management, Faculty of Education do not have smart/android phones, laptops, and Internet access to participate in the study. The researchers overcame this problem by employing a purposive sampling technique that gave room for only those who met the study's requirements to form the study's sample size.

2. Most of the students did not have a Google mail (Gmail) account that would have enabled them to access the Google classroom. The researchers overcame this problem by assisting many respondents in creating Gmail accounts.

Author contributions: All authors were involved in concept, design, collection of data, interpretation, writing, and critically revising the article. All authors approve final version of the article.

Funding: The authors received no financial support for the research and/or authorship of this article.

Acknowledgements: The authors thank a Ph.D. student, Mrs. Nnennaya Orji, for assisting the research respondents to create Gmail accounts and download Google classroom applications on their mobile phones. The authors also thank Dr. Harriet Agbarakwe for helping in the administration and collection of the test instrument.

Declaration of interest: Authors declare no competing interest.

Data availability: Data generated or analysed during this study are available from the authors on request.

\section{REFERENCES}

Bell, K. (2015). Student's quick guide to google classroom. www.ShakeUpLearning.com

Bin Mohd Jalaludin, M. A., \& Bin Ihkasan, M. N. (2014). Interpersonal communication skills among the master's students in TVET. Developing Country Studies, 4(16), 110-119. 
Iksan, Z. H., Zakaria, E., Mohd Meerah, T. S., Osman, K., Lian, D. K. C., Mahmud, S. N. D., \& Krish, P. (2012). Communication skills among university students. Procedia - Social and Behavioral Sciences, 59, 71-76. https://doi.org/10.1016/j.sbspro.2012.09.247

Jannatul-Ferdows, S. M., \& Ahmed, Z. (2015). An empirical investigation of information skills among undergraduate students at Dhaka University. Library Review, 64(4/5), 274-284. https://doi.org/10.1108/LR-11-2014-0132

Linjawi, A. I., \& Alfadda, L. S. (2018). Students' perception, attitudes, and readiness toward online learning in dental education in Saudi Arabia: A cohort study. Advances in Medical Education and Practice, 9, 855-863. https://doi.org/10.2147/AMEP.S175395
Negin, S., Ahmadi, S., Hejazi, E., \& Babakhani, N. (2016). Investigating the impact of interpersonal communication skills on social development among female students. TENDENZEN, 25(3), 10981111.

Quail, M. Brundage, S. B., Spitalnick, J., Allen, P. J., \& Beilby, J. (2016). Student self-reported communication skills, knowledge and confidence across standardised patient, virtual and traditional clinical learning environments. BMC Medical Education, 16, 73. https://doi.org/10.1186/s12909-016-0577-5

Unicheck Team (2017). Google classroom: Perfect way to improve learning process. https://unicheck.com/blog/google-classroom-to-improvelearning-process 


\section{APPENDIX 1}

\section{Google Classroom Communication Skills Test (GCCST)}

Instruction: Answer all questions.

Mat No:

Gender: Male

\section{Female}

1. is an online learning platform.
a. WhatsApp
b. Google Classroom
c. Streaming
d. Skype

2. Online learning platform promotes all of the following except
a. collaboration
b. communication c. streamlining of assignment d. movement

3. Google Classroom can be accessed through the following except
a. Computer
b. Tablets
c. Smart/Andriod phones
d. Mp3 Player

4. is the Web address a user can go to in order to sign in to Google Classroom.
a. classroom.google.com b. google.classroom.com c. googleclassroom.com
d. classroomgoogle.com

5. To sign in to Google classroom, a user must have
a. gmail account
b. ymail account
c. email account
d. mmail account

6. To add yourself to a class as a student, you must click in Google classroom.
a. Add a class
b. Join a class
c. Start a class
d. Create a class

7. All of these are the major features of Google classroom except.
a. Submit b. Classwork
c. People d. Stream

8. To post information on the Stream page, click
a. Share something with your class
b. Post something to your class
c. discuss something with your class

d. communicate with your class

9. You can add an image, file, video, or link to a post on the Stream page from the following sources except
a. Computer/phone b. YouTube
c. Drive
d. Paper

10. You can delete a comment another person created in Google classroom.

a. True b. False

11. You can send a private comment to your teacher in Google classroom by clicking a. assignment/question b. stream page c. comment d. people page

12. Assignments in Google classroom often appear in the
a. Stream page
b. Grades c. Post
d. People

13. feature appears when you want to submit an assignment with files attachment.
a. Turn in b. Mark as done
c. Submit d. Unsubmit

14. ___ feature appears when you want to submit an assignment without file attachment.
a. Turn in b. Mark as done
c. Submit d. Unsubmit

15 . feature helps you to answer questions or quiz directly from Google classroom.
a. Turn in b. Mark as done
c. Submit d. Unsubmit

16. The grade page in Google classroom helps you to see all the following works assigned to you except
a. assignments
b. questions
c. quizzes d. comments

17. Which of these cannot be a status of assigned work in the grade page?
a. turned in b. done late
c. missing d. post

18. To email your teacher or classmates in Google classroom, you must click the following.
a. People and email
b. Email
only c. People only
d. Stream and email

19. ___ must be clicked to access your grades in Google classroom.
a. Grade page
b. Classwork page Stream page
d. People page

20. All files or attachments sent to Google classroom can also be accessed directly from
a. Google Drive
b. Phonebook
c. Email folder
d. Photo gallery 


\section{APPENDIX 2}

Effect Size (r) for hypothesis $1=\mathrm{z} / \sqrt{ } \mathrm{N}$

$\mathrm{Z}=6.84$

Group $(\mathrm{N})=70$

$\mathrm{r}=6.84=6.84=0.82$

$\sqrt{ } 708.37$

\section{APPENDIX 3}

\begin{tabular}{cccccccc}
\hline & \multicolumn{4}{c}{ Tests of Normality } & \multicolumn{3}{c}{ Shapiro-Wilk } \\
\cline { 2 - 9 } & Statistic & Kolmogorov-Smirnov ${ }^{\text {a }}$ & Sf & Sig. & Statistic & df & Sig. \\
\hline Posttest & .176 & 70 & .000 & .895 & 70 & .000 & 70 \\
\hline
\end{tabular}

a. Lilliefors Significance Correction

\section{APPENDIX 4}

\begin{tabular}{|c|c|c|c|c|c|}
\hline \multicolumn{6}{|c|}{ Levene's Test of Homogeneity of Variance } \\
\hline & & Levene Statistic & df1 & df2 & Sig. \\
\hline \multirow{4}{*}{ Pretest } & Based on Mean & .153 & 1 & 68 & .697 \\
\hline & Based on Median & .672 & 1 & 68 & .415 \\
\hline & Based on Median and with adjusted df & .672 & 1 & 67.126 & .415 \\
\hline & Based on trimmed mean & .324 & 1 & 68 & .571 \\
\hline
\end{tabular}

